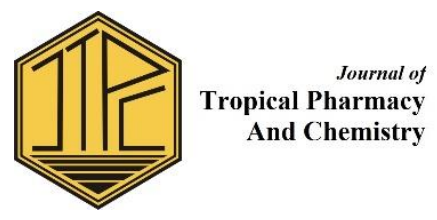

\title{
Review of Phytochemicals and Its Biological Activities and Contemporary Nutraceuticals
}

\author{
Laode Rijai \\ Research and Development of Pharmaceutical Laboratory of FARMAKA TROPIS \\ Faculty of Pharmacy Mulawarman University, Samarinda, Kalimantan Timur, \\ INDONESIA \\ email: najwankhanrjai@yahoo.co.id
}

\begin{abstract}
Nutraceutical is food for health with functions of preventive, promotive, rehabilitation, aesthetic, intelligence to curative. Nutraceuticals as food products can have a contemporary value, which is a trend or extraordinary circumstance that attracts consumers because of its function as a supplement, functional food, medical food, and genetically engineered food so that it penetrates the world market without limits. Nutraceuticals that are contemporary make it easy to achieve the goals of health care by using the "nutraceuticals" approach because the client wishes to himself with a high level of confidence in the benefits of the product for health and therefore uses it. Potential compound for nutraceuticals is secondary metabolites because it has multipotential for health, but specific to certain functions. Secondary metabolites, generally sourced from low plants and animals, because these biological groups do not have a perfect secretion system so that metabolites resulting from secondary metabolism are stored in cells and tissues properly, with several functions, among others, for defense and attractiveness of the biological. Some of the classes and compounds of plant secondary metabolites that are known to have potential for nutraceuticals are Terpenoids, Terpenoids non-Carotenoids, Polyphenolics, Phenolic Acids, Non-Flavonoid Polyphenolics, Glucosinolates, Thiosulphinates, Phytosterols, Anthraquinones, Glucosamines, Octacosanolines, Characticines, Chines) Pectin, Pigments, Tocotrienols and Tocopherols, Ubiquinon and $\square$-Lipoic Acid. Furthermore, some contemporary nutraceuticals are Spiruline, Broccoli, Aloe Vera Gel and Aloe Juice, Soyfoods, Omega-3- Fatty Acids, Pomegranate Juice, Walnuts, and Organic Mushroom Nutrace.
\end{abstract}

Keywords: Nutraceuticals, Phytochemicals, Contemporary

Submitted on: 19 August 2019

Accepted on: 09 September 2019

DOI: https://doi.org/10.25026/jtpc.v4i6.216

\section{INTRODUCTION}

Illness or abnormal conditions of metabolism of living things including humans, because there has been a damage to the metabolic system that causes loss or decline in the function of a metabolite or 
biomolecules in cells and tissues so that metabolism does not take place as it should. Healing or repairing the metabolic damage, of which not all of them become normal, but the condition remains abnormal even though it does not appear to interfere in the survival of the mammal. Abnormal metabolic conditions have the potential to occur again with the same type of case, or cases that are not the same. This happens because metabolism is systemic or interrelated with one another so that the total healing of metabolic damage without producing new effects is difficult to obtain, unless the stage of abnormal conditions is still very low. Therefore, the management of the health of a community or country that only focuses on curative or healing diseases is worthless. The health management of a community or country with a curative approach creates many new problems including high costs for health services and pharmaceutical products that are used, so that the recovery is not obtained by patients, but an increase in the stage of illness until the number of health cases increases as a result of psychological costs. In addition, some people giving up recovering as a result of the cost of health services.

Relatively appropriate health management is the maintenance of individual health continuously with preventive and promotive approaches. Preventive and promotive implementation can use learning methods for knowledge of healthy behaviors and or use of pharmaceutical products that are believed to have preventive and promotive effects. Supporting methods for health management with a preventive and promotive approach is the examination of health conditions at an early age on a scheduled basis. This is to find out preventive and promotive methods that are relevant for each individual. The weakness of the preventive and promotive approach with learning or counseling methods for knowledge of healthy behaviors is that individual compliance is generally weak, whether it is against prohibitions or suggestions or commands, unless the person has experienced illness. That is why the curative principle in health management is still the most effective and preferred strategy by many people. Learning methods for knowledge of healthy behaviors have been implemented by the Indonesian government, but the results are difficult to measure because the increase in sufferers of degenerative diseases still occurs. Learning methods for knowledge of healthy behaviors in the community, scientifically implemented by Public Health expertise.

Furthermore, the management of public health with a health care approach to preventive and promotive methods can also be carried out with methods of using pharmaceutical products that are trusted and reliably preventive and promotive. This approach has been well studied in pharmaceutical science and has produced several products for health (preventive and promotive, in addition to curative and rehabilitation, aesthetics, and intelligence). All these functions are in the form of pharmaceutical products as medicines, nutraceuticals, cosmetics, and medical devices. The aspects of pharmaceutical scientific assessment of the object are quite detailed, namely (a) science and technology search for the discovery of raw materials for drugs, cosmetics, nutraceuticals, medical devices from natural or synthetic resources (b) science and technology engineering for the manufacture of pharmaceutical products as pharmaceutical, cosmetic products, nutraceuticals and medical devices from these raw materials (c) science and technology of the use of pharmaceutical products for health, fitness and intelligence as well as distribution to the public (d) science and technology of quality assurance and safety of raw materials and 
pharmaceutical products as well as quality and safety of use pharmaceutical products for health and for distribution to the public. Nutraceutical an object of pharmaceutical scientific learning as a pharmaceutical product with benefits as preventive, promotive, rehabilitation, aesthetic, intelligence to curative. Nutraceuticals are formulated into pharmaceutical products with benefits as functional foods, supplements, medical foods, and foods for genetic engineering. The four functions of nutraceuticals are worth maintaining health in the form of preventive, promotive, rehabilitation, aesthetic, intelligence to curative. Besides nutraceuticals as food can be formulated and produced with high promotional value because of its function so that it attracts the attention of consumers to use it. However, the requirements for nutraceuticals products are quality and safe.

The most important chemical compound as a nutraceutical with multi functions is secondary metabolites. Most secondary metabolites from plants and a few low animal levels. The kind of that compounds are so many in Indonesia as a tropical country with a variety of biodiversity. The purpose of this article is to complete the collection and collection of secondary metabolites that are questioned as nutraceuticals. The benefit is the management of health from curative to preventive using pharmaceutical products, namely nutraceuticals. Utilization of secondary metabolites as nutraceuticals can be done in the form of extracts with minimal requirements related to the type of composition in the extract, especially those that have benefits as nutraceuticals, both as medical foods, functional foods, supplements and genetically modified foods. Furthermore, the product can be used, so that, it is safe, and effective to be used as a health product for prevention, promotion, rehabilitation, rehabilitation, intelligence improvement to disease. The difference in biological activity between compositions in one biological as a different source, scientific sources can engineer products for the potential of these nutraceuticals to have functions for the health that humans need. Because it is a nutraceutical source that is not based on its source, but as a product-based formulations consisting of biological sources or the compositions thus producing the nutraceutical products that are needed by humans for health. Thus, nutraceuticals are very likely to penetrate the world market with the term contemporary nutraceuticals.

\section{METHODS}

This article presents several groups of secondary metabolites from plants as well as several types of compounds potential nutraceuticals as pharmaceutical products for health maintenance to healing. In addition, it also presents several contemporary nutraceutical products that are produced in the form of artistic value and high-level promotion to attract the attention of consumers so that they are willing to use it and finally maintenance to health healing can be realized. The study approach is a review conducted with comprehensive to synthetic analysis techniques using the literature study method of several scientific articles and research reference books related to the study material. Reference books used include (a) Pharmacognosy and Pharmacobiotechnology (b) Organic Chemistry and Medicine (c) Phenolics in Food and Nutraceuticals (d) The Functional Foods of Revolution (d) Agricultural Medicine (e) Medicinal Natural Products (f) Modern Phytomedicine (f) Method of Analysis for Functional Foods and Nutraceuticals. In addition, direct literature studies articles in several scientific magazines. 


\section{RESULTS AND DISCUSSION}

The results of the literature study have found several groups of secondary metabolites as well as several types of compounds that have the potential as nutraceuticals for functional foods, supplements, medical foods, and genetically modified foods. The results of the literature review presented are several groups and potential compounds as nutraceuticals as well as several nutraceuticals that have reached the contemporary i.e. a nutraceuticals product of high artistic value and promotion because of its function for health and have penetrated the world market.

\section{A. Phytochemicals and Its Biological Activities}

Nutraceuticals are substances or food products for health with preventive, promotive, rehabilitation, aesthetic, intelligence to curative functions. This pharmaceutical product is still lacking in public interest due to health improvement through curative after pain recovery. The concept of health care through promotion and promotion has been carried out by studying the learning of healthy behaviors through the method of discussion until discussion, but did not achieve maximum results, because the discussion at the top level of clients related to the prohibition and recommendations for health is very low. Related to the use of pharmaceutical products, namely nutraceuticals Supporting health prospects, because with its symbol as food, nutraceutical products can be engineered through pharmaceutical science that produces high-value artistic and promotional products related to the utilization of its benefits. In this article, several types of secondary metabolites of plants are presented as well as several types of active nutraceuticals that are functional for preventive, promotive, rehabilitation, ethics, intelligence to curative. The main requirement for nutraceutical products is quality and safety.

\section{Group of Terpenoids or Isoprenoids}

Chemically, terpenoids are an oxygenated terpene, and the precursor of terpenoids is isoprene forming monoterpene, diterpene, triterpene, and tetraterpene. The most potential terpenoids secondary metabolites as nutraceuticals are Carotenoids and some non-carotenoids.

\section{a. Carotenoid Terpenoids}

The function of carotenoids in humans is very much in accordance with the types of carotenoids themselves. Some important carotenoids are orange like carotenoids $\alpha, \beta$, and $\gamma$ caroten; red carotenoids like licopene and astaxantin; yellow carotenoids such as lutein and zeaxantin. About 600 types or more carotenoids have been isolated from various of plants. Roughly $50 \%$ types of carotenoids are required by human, and 30 $\%$ of that requirement are lycopene and $\beta$ carotene. Lycopene identical with $\Psi \Psi$ Carotene and all trans-Lycopene. The characteristics are red in tomatoes, papaya, melons, and various fruits that are purple or pink. Furthermore, $\quad \beta$-Carotene synonymous with Carotaben, Provatene, dan Solatene. The main uses are as antioxidants, as well as stimulating enzymes for DNA normalization. $\alpha$ Carotene has 10 times more anticarcinogenic properties than $\beta$-Carotene; Xanthophyll synonymous with Lutein, $\beta, \varepsilon^{-}$ Carotene-3,3'-diol. Its characteristics are protecting vitamins $\mathrm{A}, \mathrm{E}$ and other carotenoids; henceforth Zeaxanthin is synonymous with $\beta, \beta$-Carotene-3,3'-diol and all compounds with position trans $\beta, \beta$ Carotene-3,3'-diol; Zeanthatol and Anchovyxanthin. Other carotenoids are Astaxanthin with the synonym Ovoster 3,3'-dihydroxy-4,4'diketo- $\beta$-carotene. Its antioxidant activity is stronger than other 
carotenes. All these compounds are powerful antioxidants as nutraceuticals.

\section{b. Non-Carotenoid Terpenoids}

Important terpenoids including nutriceuticals are non-carotenoids terpenoids such as limonoies (terpene limonoids) which are found in orange peels, namely d-limonene, pinene, eucalyptol. The d-Limonene compound is synonymous with Cajeputener, Cinene, Kautschin. Other non-carotenoids compounds are saponins, $\alpha$-terpinol. Saponins has very broad uses. Both of these compounds are supplements.<smiles></smiles>

D-Limonen with synomin Cajeputener, Cinene, Kautschin<smiles>CC1=CCC(C(C)(C)O)CC1</smiles>

Figure 1. Stucture of D-Limonen and $\alpha$-Terpinol

\section{Polyphenolics}

Polyphenolics in extract form are very powerful antioxidants and have been used as nutraceuticals and almost all plants are polyphenolics. Polyphenolics are chemically classified into 3 groups namely Flavonoids Polyphenolics, Phenolics Acid, and Non-Flavonoid Polyphenolics.

The characteristics of flavonoid polyphenolics are antioxidants and some anti-inflammatory. Chemically there are two important structural models and the derivatives of these two structures are very numerous as flavonoid compounds. These important structures are:<smiles>O=c1cc(-c2ccccc2)oc2ccccc12</smiles><smiles>Oc1ccc(/C=C/c2cc(O)cc(O)c2)cc1</smiles>

Resveratol

Figure 2. Structure ofe Flavone and Resveratol

Almost all citrus fruits contain flavonoids such as routine compounds, hesperidin, and naringin. Hesperidin and naringin are polyphenolic glycoside. Other polyphenolics flavonoids are Anthocyanins with their color characteristics and antioxidants. Some Anthocyanins compounds are Cyanidin, Delphinidin, Malvidin, Pelargonidin, Peonidin, Petunidin. Furthermore, other polyphenolics are Catechin synonymous with Catechol, Catechinic Acid, Catechuic 
acid, Dexcyanidanol, Cyanidanol, and Catergen, with chemical structures:<smiles>Oc1cc(O)c2c(c1)O[C@H](c1ccc(O)c(O)c1)[C@H](O)C2</smiles>

Figure 3. Structure of Catechin

This Catechin group has two molecular forms namely monomeric molecules including Catechin and Epicatechin; and Dimeric molecules such as Procyanidins B1 and B2. The usefulness of the compound catechin is antioxidant chocolate, inhibits the enzyme catechol-Omethyl transferase in degrading norepinephrine, preventing and stopping cancer growth, protecting DNA from treatment with radiation therapy or chemotherapy. Catechin is found in tea leaves. Catechin polymer is a tanin present in black tea.

Other important polyphenolics flavonoids are Isoflavones or 3phenylchromone which are phytonutrients that are found in peas and these polyphenols are believed to be good for prostad cancer. Other known polyphenolics flavonoids are hesperetin, naringin, routine (synonyms: Rutoside, Melin, Phytomelin, Eldrin, Llixathin, Sophorin, Globularicitrin, Plaiuroside, Osyritin, Osyritrin, Mytriolorin, Violaquercitrin, and Birutan). All these compounds are found in Asparagus. Other important polyphenolics flavonoids are Querecetin with the synonyms of Sophoretin, Cyanidenolon, as well as a number of other polyphenol flavonoids that have been used as nutriceuticals.

\section{Phenolic Acids}

This group of compounds is found in cranberry juice, prevents urinary tract infections, prevents the work of cancer promoters. Compounds that are classified as Phenolics Acids are Ellagic Acids (synonyms: Benzoaric Acid and Lagistase), Chlorogenic Acid; p-Coumaric Acid (synonym: p-hydroxy cinnamic acid; $\square$ - [4-hydroxy phenyl acrylic acid); Phitic acid (synonym: Alkalovert); Cinnamic Acid or $\square$-Phenylacrylic).<smiles>O=C(C=Cc1ccc(O)c(O)c1)O[C@@H]1C[C@](O)(C(=O)O)C[C@H](O)[C@H]1O</smiles>

Chlorogenic Acid<smiles>C=C(O)C=Cc1ccc(O)c(O)c1</smiles>

Caffeic Acid

Figure 4. Structure of Chlorogenic Acid and Caffeic Acid

Another phenolic acid is Ellagic Acid with the synonym Benzoaric Acid found in Strawberry which has the potential to reduce the risk of Colon cancer.

\section{Non-Flavonoid Polyphenolics}

Chemically, this group of compounds does not have benzopyran nucleus. The amount of this compound is relatively small such as curcumin (synonym: Tumeric yellow); resveratrol 
and lignans. The main uses of polyphenolics are also antioxidants. Curcumin component of the primary secondary metabolite of turmeric (Trumeric) in Rhyzomes, which acts as a protective gene, is a powerful antioxidant, and treats gastritis. Furthermore, resveratrol as an anti-inflammatory by inhibiting the COX-1 enzyme. Another example of non-flavonoid polyphenol compounds is lignans which are abundant in all plants.<smiles>COc1cc(/C=C/C(=O)CC(=O)/C=C/c2ccc(O)c(CO)c2)ccc1O</smiles>

Curcumin<smiles>Oc1ccc(CCc2cc(O)cc(O)c2)cc1</smiles>

Figure 5. Structure of Curcumin and Resveratrol

\section{Glucosinolates atau Thioglucosides}

The basic structure of this class of compounds has glucose, sulphate residues, various aglycones, which are formed from amino acid precursors. This group of compounds is found in vegetables, especially broccoli and has been known to prevent colon cancer. Some classes of compounds including glucosinolates are isothiocyanates namely Phenylisothiocyanate, Sulforaphane compounds. Furthermore, Indoles such as Indole-3-carbinol, which have been known to inhibit the Human Papilloma Virus (HPV) and are found in broccoli.

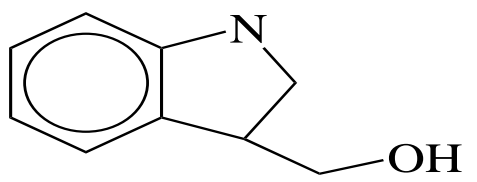

Indole-3-Carbinol<smiles>S=C=NCCc1ccccc1</smiles>

Phenethyl Isothiocyanate<smiles>CS(=O)(=O)C=CCCN=C=S</smiles>

Sulforaphane

Figure 6. Structure of Indole-3-carbinol, Phenyl isothiocyanate, and Sulforaphane

\section{Thiosulphinates atau Cystein Sulphoxides}

These compounds have tubers, especially garlic. Its use is quite a lot including preventing pests on onions, lowering blood pressure in humans. The well-known compound of this class is Allicin (Diallyl Thiosulphate) found in garlic (Allium sativum).

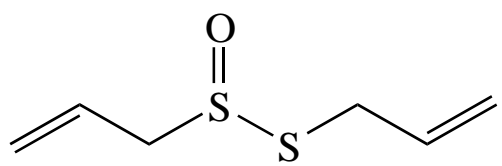

Figure 7. Structure of Allicin (Diallyl Thiosulphinate) 


\section{Phytosterols}

Phytosterols as if the plant cholesterol and which is commonly found is $\beta$-Sitosterol with synonyms $\alpha$ Phytosterol, Cinchol, Cupreol, Rhamnol, Quebrachol, Sitosterin, Harzol, Prostasal, and Sito Lande. There are quite several uses, including blocking the development of tumors (neoplasms) in the colon. These compounds are found in green and yellow vegetables.

\section{Anthraquinones}

Anthraquinones are usually characterized by phenolic and glycosidic and are derived from anhtrone compounds. Anthraquinones and Hydroxyanthraquinone derivatives include Aloe-emodin, Crysophanol, Emodin, Rhein.<smiles>O=C1c2ccccc2C(=O)c2ccccc21</smiles>

Anthraquinone<smiles>O=C1c2ccccc2Cc2ccccc21</smiles>

Anthrone<smiles>Oc1c2ccccc2cc2ccccc12</smiles>

Anthranol

Figure 8. Structure of Anthraquinone<smiles>[R5]C1c2cccc(O)c2C(=O)c2cc(CO)cc(O)c21</smiles>

Barbaloin<smiles>OCc1cc(O)c2c(O)c3c(O)cccc3c(Cl)c2c1</smiles>

Barbaloin (Anthranol Tautomer)<smiles>[R5]C(Cl)c1c(O)cc(C)cc1C(O)c1c(O)cccc1Cl</smiles>

Chrysaloin (Deoxybarbaloin)

Figure 9. Structure of Barbaloin, Barbaloin (Anthranol Tautomer), and Chrysaloin (Dexybarbaloin) 
The compounds that are included Anthraquinones quite a lot in nature and very potential in the pharmaceutical field and have been found in plants. The use of anthraquinones compounds and their inheritance include controlling diabetes, improving the human immune system, preventing AIDS, preventing asthma, protecting kidney function, and so on. Some other compounds as Anthraquinone is a group of Senna which is found from the leaves of Cassia senna, namely Sennosides $A$ and B, Glucosides Rhein and Chrysophanic acid. Another anthraquinone is Barbaloin which is dominant on the stem of the Cascara plant and is a glycoside compound. The use of the compound Barbaloin to control diabetes, protect the human immune system, prevent AIDS, prevent Astma, protect the kidneys and cough, Arthritis, controlling blood cholesterol levels, detox, and skin problems.

Other Anthraquinones Hypericin (Synonym: Red Hypericum) is a red pigment found in Hypericum perforratum. The compound is used as an analgesic or neuralgic.

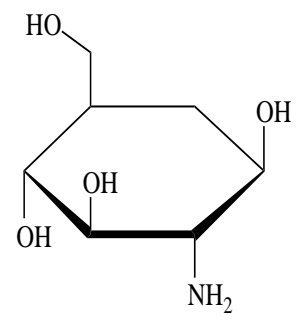

Figure 10. Structure of Glucosamine

\section{Glucosamine Chitosamine)}

(Synonim:

Glucosamine is found in Chitin, mucoprotein, and micro polysaccharides that form naturally in plants. Glucosamine is also produced naturally in the human body, especially in cartilage, tendons, and ligament tissue. The usefulness of Glucosamine related to arthritis, such as reumatic arthritis (RA), osteoarthrhitis (OA) and several other degenerative diseases.

\section{Octacosanol (Synonim: Octacosyl Alcohol)}

Octacosanol is found in vegetable leaf wax, and also the bark of various plants. the chemical formula of this compound is a long and straight chain $\mathrm{H}_{3} \mathrm{C}\left(\mathrm{CH}_{2}\right)_{26} \mathrm{CH}_{2} \mathrm{OH}$. The function of this compound is known as an athlete supplement, Parkinson's drug, and cholesterol lowering.

\section{Chlorophyll}

Chlorophyll, a green pigment found in almost all plants, especially those that are green. In higher plants and green algae (green algae) contain Chlorophyll a and Chlorophyll $\mathrm{b}$ with a ratio of 3 : 1 ; while Chlorophyll $\mathrm{C}$ is also found in marine algae. The benefits that have been used for chlorophyll are maintaining digestive health, gum health, reducing the risk of diabetes, maintaining general health of the body. Chemically, there are two Chlorophyll namely a and $\mathrm{b}$.

\section{Phytochemical Pigments}

Pigment compounds found in fruits and vegetables have a very good effect on nutraceuticals as an attraction and also have health benefits, including Chlorophyll, and various Carotene compounds.

\section{Tocotrienols dan Tocopherol}

Both compounds are found in grains, especially wheat and palm oil. Both compounds each have isomers namely $\alpha$ and $\beta$ Tocotrienol and $\alpha$ and $\beta$ Tocopherol. Compounds $\alpha$ and $\beta$ Tocotrienol are both found in wheat grains, while $\alpha$-Tocopherol 
in green vegetables, wheat, palm oil; the growth of breast cancer; whereas whereas $\beta$-Tocopherol is formed naturally Tocopherol's biological activity is similar from vitamin E. Tocotrienols can inhibit to vitamin E. Tocotrienols also reduce cholesterol<smiles>CC(C)=CCC/C(C)=C/CC/C(C)=C/CC[C@]1(C)CCc2c(C)c(O)c(C)c(C)c2O1</smiles><smiles>CC(C)=CCC/C(C)=C/CC/C(C)=C/CC[C@]1(C)CCc2c(C)c(O)cc(C)c2O1</smiles><smiles>CC(C)=CCC/C(C)=C/CC/C(C)=C/CC[C@]1(C)CCc2c(C)c(O)c(C)c(C)c2O1</smiles><smiles>CC(C)=CCC/C(C)=C/CC/C(C)=C/CC[C@]1(C)CCc2c(C)c(O)cc(C)c2O1</smiles>

Figure 11. Structure of $\alpha$-Tocotrienol, $\beta$-Tocotrienol, $\alpha$-Tocopherol, and $\beta$-Tocopherol. 


\section{B. Phytochemicals and Bioactivities for Contemporary Nutraceuticals \\ Definition of "Contemporary}

Nutraceuticals" is a trend or extraordinary state of a nutraceuticals because its functional information for health becomes super very attractive to consumers to penetrate the world market without limits (Sumathi, et al., 1993). Nutraceuticals as food; with the function of preventive, promotive, rehabilitation, fitness, curative to intelligence could become a contemporary product. Fitness functions for example related to beauty or beauty that are healthy and fit; promotive function related to healthy stamina to curative function; if you have a nutraceutical product, then with a provocative information system the consumer will make it as a necessity. Pharmaceutical Science through Pharmaceutical Technology can engineer a nutraceutical product that has these six functions. Therefore, pharmaceutical scientific engineering nutraceuticals become very appropriate as a health management strategy. Clients enjoy nutraceuticals products with the basis of attractiveness that is enjoyable and energetic as well as getting benefits, namely avoiding health problems, having optimal stamina so that they look fit, beautiful and healthy. Other functional functions that can be integrated with several functions are intelligence and curative. Therefore, in addition to the biological activity profile of a nutraceutical compound which is very important, the provocative ability of product engineering and information systems is also very important; so, it has the opportunity to become contemporary nutraceuticals.

Some contemporary nutraceutical products are:

a. Spirulina (Spirulina platensis) A cyanobacterium can overcome people who have been exposed to commercialized malnutrition and is a product of seaweed with a certain chemical composition

b. Broccoli (Brassica oleraceae italica) contains glucarophanin that is a precursor of sulphoraphane which is very good for detoxes including toxic carcinogens through the induction of enzymes that act as detoxics, prevent breast cancer, colon cancer, stomach cancer and ulcers, and various other cancers

c. Aloe Vera Gel and Aloe Juice with various benefits, namely various antibacterial, controlling diabetes, increasing the immune system; and others like cosmetics.

d. Soyfoods from soybeans with uses such as slowing down female menopause, and strong antioxidants

e. Omega-3-Fatty Acids, which is commonly found in fish oil with the main uses as the main constituent of brain cells, lowering cholesterol, antiinlamatory, reumatic, etc.

f. Pomegranate Juice, powerful antioxidant, protects DNA, antiatherosclerotic, lowers cholesterol by oxidation, and prevents coronary heart disease

g. Walnuts, as the antioxidant hormone melatonin, blood circulation, by melatonin compounds and is also able to improve oxidative stress. Because it is made as a supplement.

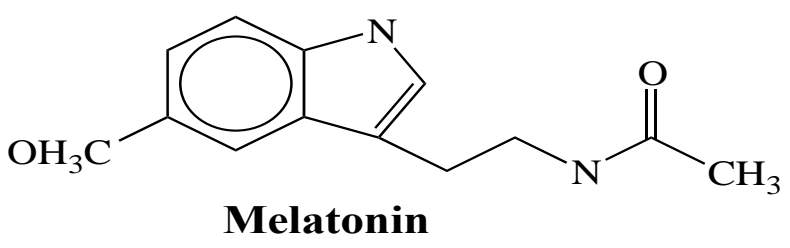

Figure 12. Structure of Melatonin 
h. Organic Mushroom Nutrace; low calorie nutraceutical, high protein, iron $(\mathrm{Fe})$, zinc, chitin. Nutraceutica has become TCM (traditional Chinese Medicine) as a probiotic, antiresistant. The famous Mushroom Nutrace product is Trymio-Gen ${ }^{\mathrm{TM}}$ dan MycolPlex- $7^{\mathrm{TM}}$.

\section{CONCLUSIONS}

a. Nutraceuticals have the potential and are suitable as pharmaceutical products for the maintenance and improvement of health quality through the function of chemical compounds that contain as preventive, promotive, rehabiltation, aesthetic, intelligence, to curative

b. Nutraceuticals in this function can be formulated in the form of nutraceutical products as functional foods, supplements, medical foods, and engineering foods.

c. Some of the Natural Chemistry Products that are proven to be compounds of nutraceuticals are Terpenoids, Terpenoids nonCarotenoids, Polyphenolics, Phenolic Acids, Polyphenolics Non-Flavonoid, Glucosinolates, Thiosulphinates, Phytosterols, Anthraquinones, Glucosamines, Octacosanoline Chines, Chlorine, Chines) Pigments, Tocotrienols and Tocopherols, Ubiquinon and $\alpha$-Lipoic Acid.

d. Some nutraceuticals that have been contemporary are Spiruline, Broccoli, Aloe Vera Gel and Aloe Juice, Soyfoods, Omega-3- Fatty Acids, Pomegranate Juice, Walnuts, Organic Mushroom Nutrace.

\section{RECOMMENDATIONS}

a. Health management should be the maintenance of health with a preventive and promotive approach through the use of Nutraceuticals. b. Pharmacy Higher Education in Indonesia should in addition to drugs and medical devices, also focus on the discovery of Nutraceuticals, because it has biological and non-biological natural resources for pharmaceuticals that are very abundant, as well as nutraceuticals primarily oriented to health care services

c. Natural Products Chemistry as a Nutraceuticals raw material that has been known and found in Indonesia, is immediately followed up in the aspect of searching for new source discoveries, manufacturing products in the form of nutraceuticals that have the potential to be Contemporary Nutraceuticals and specifically the specific raw materials for nutraceuticals and found in Indonesia, called Contemporary Nutraceuticals Indonesian.

\section{REFERENCES}

[1] Ahmad, I., F. Aqil, and M. Owais. 2006. Modern Phytomedicine: Turning Medicinal Plants into Drugs. Wiley-VCH Verlag GmbH \& Co. KgaA

[2] Arruzazabala. 1993. Leucot, Essent, Fatty Acid. In Pharmacognosy And Pharmacobiotechnology. A. Kar. 2009, Revised-Expanded Second Edition (11: 735-777). New Age International (P) Limited Publishers. New Delhi, India

[3] Brower, V. 1998. Nutraceuticals Poised for Healty Slice of Healtheare Market, In Pharmacognosy And Pharmacobiotechnology. A. Kar. 2009, Revised-Expanded Second Edition (11: 735-777). New Age International (P) Limited Publishers. New Delhi, India

[4] Denham, K. J. and A. Thelin. 2016. Agricultural Medicine: Rural Occupational and Environmental Health, Safety, and Prevention, 
Second Edition. First Published. John Wiley and Sons. Inc.

[5] Dinsmore, J. 2012. Organic Chemistry and Medicine. Organicchemist. ACS.

[6] Dewick, P. M. 2009. Medicinal Natural Products: A Biosynthetic Approach, 3rd Edition. John Wiley and Sons. Inc. Ltd.

[7] Heasmen, M. and M. Julian, 2001. The Fungsional Food Revolution: Healthy People, Healthy Profits. Fisrt Publish, Routledge (Pub). UK and USA.
[8] Hurst, J. W. 2008. Methods of Analysis for Functional Foods and Nutraceuticals, 2nd Edition. CRC Press.

[9] Shahidi, F. and Naczk, M. 2003. Phenolics in Food and Nutraceuticals. CRC Press.

[10] Snider, SR. 1984. Octaciosanol in Parkinsonism, In In Pharmacognosy And Pharmacobiotechnology. A. Kar. 2009, Revised-Expanded Second Edition (11: 735-777). New Age International (P) Limited Publishers. New Delhi, India 